\title{
Bundling Strategy For A Follower
}

\author{
Ming-Chung Chang, Kainan University, Taiwan
}

\begin{abstract}
A follower in a market always uses a bundling strategy as a marketing strategy to increase profit and to change its market status. In this paper, the relationship between the main goods and bundling goods is substitutive, independent, or complementary. A Stackelberg game is applied to capture the competitive relationship between a leader and a follower. A follower uses a bundling strategy as a marketing strategy, but a leader does not. This study reveals that a follower will become a leader when he (or she) sells two products that are low substitution goods. However, it induces a social welfare to decrease when a follower bundles goods. This paper illustrates that a bundling action can invert a follower's market status. However, the inversion on a follower's status does not promote the social welfare.
\end{abstract}

Keywords: Bundling Strategy, Stackelberg Game

\section{INTRODUCTION}

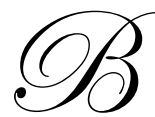

undling is when various goods are bundled in a package and sold at the same time. Bundling is a marketing strategy for extracting consumer surplus and for increasing commercial profit. The marketing strategy of bundling is seen in the financial industry, tourism industry and others. For example, some financial institutions bundle a credit card with travel, insurance, or airport service. Tourism usually bundles a travel program with plane tickets, travel insurance, or a hotel.

The earliest literature about bundling aimed at the economic effect of bundling two goods under the monopoly market structure (Burstein, 1960; Adams and Yellen, 1976; Schmalensee, 1982; Schmalensee, 1984; MacAfee et. al., 1989; Salinger, 1995; Bakos and Brynjofsson, 1999). They found that the monopoly firm achieves profitability by bundling goods.

The literature above cannot be applied to competitive industries. Thus, some papers consider the Bertrand duopoly market structure (Chen, 1997; Vaubourg, 2006), while others discussed the Cournot duopoly market structure (Martin, 1999).

Many follower firms in practice often use the marketing strategy of bundling to compete with the leader firm in order to obtain more profit or to change their competitive disadvantage. This study discusses the follower firm's competitive advantage under a Stackelberg duopoly structure. This model setting is missing in the previous literature.

The remainder of the article is organized as follows. Section 2 presents the model setting. The model results are shown in Section 3. Section 4 offers some questions. Section 5 concludes the article.

\section{THE BASIC MODEL}

There are two firms, 1 and 2, in a Stackelberg game. Firm 1 is a Stackelberg follower and Firm 2 is a Stackelberg leader. In order to compete with the Stackelberg leader, Firm 1 has a marketing strategy of bundling. Assume that Firm 1 produces two goods, $x$ and $y$, and Firm 1 uses a marketing strategy by bundling $x$ with $y$. However, Firm 2 only makes one product $x$. The production costs for $x$ and $y$ are $c_{x}=c_{y}=c$. According to the setting of Spence (1976) and Dixit (1979), let market demand for $x$ and $y$ be derived from:

$U=\alpha+\beta(x+y)-(1 / 2)\left(x^{2}+2 r x y+y^{2}\right)$, 
where $\alpha$ represents the utility which comes from the goods except $x$ and $y$. Parameter $r$ represents the relationship of $x$ and $y$, where $r \in(-1,1)$. If $x$ and $y$ are perfect complements, then $r=-1$; if $x$ and $y$ are independent goods, then $r=0$; if $x$ and $y$ are perfect substitutions, then $r=1$.

Suppose the marketing strategy of Firm 1 is to bundle a proportion $\mu$ of $y$ when it sells one unit of $x$, i.e., $\left(\mu_{y}, 1\right)$. Define the combination $\left(\mu_{y}, 1\right)$ as bundle 1, i.e., $\delta_{1}$. Firm 2 has no marketing strategy, and thus its selling combination is $(0,1)$, i.e., $\delta_{2}$. After bundling, the productions of $x$ and $y$ are:

$x=\delta_{1}+\delta_{2}$, and $y=\mu_{y} \delta_{1}$.

Substitute Equation (2) into Equation (1), and then the market demand for $b_{1}$ and $b_{2}$ are derived from:

$U^{B}=\alpha+\beta\left[\left(1+\mu_{y}\right) \delta_{1}+\delta_{2}\right]-(1 / 2)\left[\left(1+2 r \mu_{y}+\mu_{y}^{2}\right) \delta_{1}^{2}+2\left(1+r \mu_{y}\right) \delta_{1} \delta_{2}+\delta_{2}^{2}\right]$.

\section{ANALYSIS AND EXPLANATION}

Two cases are discussed in this section: 1) Without a marketing strategy (no bundling case) and 2) with a marketing strategy (bundling case).

\section{No Bundling Case}

From Equation (1), two firms face inverse demand functions are:

$p_{1}=\beta-(x+r y)$, and $p_{2}=\beta-(r x+y)$, where $x=x_{1}+x_{2}$, and $y=y_{1}$.

The two firms' equilibrium outputs in a Stackelberg game are:

$x_{1}=\frac{1}{2}\left(\frac{1}{2}-\frac{r}{r+1}\right)(\beta-c), y_{1}=\frac{1}{2(r+1)}(\beta-c)$, and $x_{2}=\frac{1}{2}(\beta-c)$, where $\beta>c$.

Here, $y_{1}$ is Firm 1's monopoly output for $y$, while $x_{i}$ is Firm $i$ 's Stackelberg output for $x$, where $i=1$, or 2 . The two firms' equilibrium profits in Stackelberg game are:

$$
\begin{aligned}
& \pi_{1}=\frac{(\beta-c)^{2}}{8}\left(\frac{1}{2}-\frac{r}{r+1}\right)+\frac{(\beta-c)^{2}}{2(r+1)}\left[1-\frac{1}{2(r+1)}-\frac{r}{2}\left(\frac{3}{2}-\frac{r}{r+1}\right)\right], \text { and } \\
& \pi_{2}=\frac{(\beta-c)^{2}}{8} .
\end{aligned}
$$

Social welfare is the sum of consumer surplus $(U)$ and producer surplus $\left(\Sigma \pi_{i}\right)$. Because $U$ and $\Sigma \pi_{i}$ are functions of $\beta, c$ and $r$, the social welfare function also can be represented as function of $\beta, c$ and $r$. The social welfare is shown as follows:

$S W=U+\Sigma \pi_{i}=S W(\beta, c, r)$.

\section{Bundling Case}

From Equation (3), the two firms face the inverse demand functions are:

$p_{1}{ }^{B}=\left(\mu_{y}+1\right) \beta-\left[\left(1+2 r \mu_{y}+\mu_{y}{ }^{2}\right) \delta_{1}+\left(1+r \mu_{y}\right) \delta_{2}\right]$, and $p_{2}{ }^{B}=\beta-\left[\left(1+r \mu_{y}\right) \delta_{1}+\delta_{2}\right] .$.

Firm 1 bundles one unit $x$ and one unit $y$ to form its marketing strategy, i.e., $\mu_{y}=1$. The two firms' equilibrium bundles and outputs are: 
$\delta_{1}=\frac{(\beta-c)\left(2+\frac{1+r}{3-r}\right)}{4(1+r)}$, and $\delta_{2}=\frac{\beta-c}{3-r}$.

$x_{1}^{B}=\frac{(\beta-c)\left(2+\frac{1+r}{3-r}\right)}{4(1+r)}, y_{1}^{B}=\frac{(\beta-c)\left(2+\frac{1+r}{3-r}\right)}{4(1+r)}$, and $x_{2}^{B}=\frac{\beta-c}{3-r}$.

Here, $y_{1}{ }^{B}$ is Firm 1's monopoly output for $y$ under the bundling case, and $x_{i}^{B}$ is Firm $i$ 's Stackelberg output for $x$ under the bundling case. The two firms' equilibrium profits in the Stackelberg game under the bundling case are:

$\pi_{1}^{B}=\frac{(\beta-c)^{2}}{8(1+r)}\left(\frac{5-3 r}{3-r}\right)^{2}$, and $\pi_{2}^{B}=\frac{(\beta-c)^{2}}{4(3-r)}$.

The social welfare under the bundling case is shown as follows:

$S W^{B}=U^{B}+\Sigma \pi_{i}^{B}=S W^{B}(\beta, c, r)$.

\section{DISCUSSION}

This section discusses some questions. First, does the Stackelberg follower have an incentive to bundle? Second, can the Stackelberg follower become a Stackelberg leader after bundling? Third, compare the social welfare under the no bundling case and the bundling case.

\section{Bundling Incentive for a Stackelberg Follower}

From Equations (6) and (6'), if $\pi_{1}^{B}-\pi_{1}>(<) 0$, then Firm 1 has (not) an incentive to bundle $x$ with $y$. It is obvious that increasing on Firm 1's cost from $c$ to $c$ ' induces a decrease on Firm 1's profit no matter in the bundling case or in the no bundling case. From Figure 1, when two products are highly complementary, it is good for the firm not to bundle. When two products have high substitution, it is good for the firm to bundle.

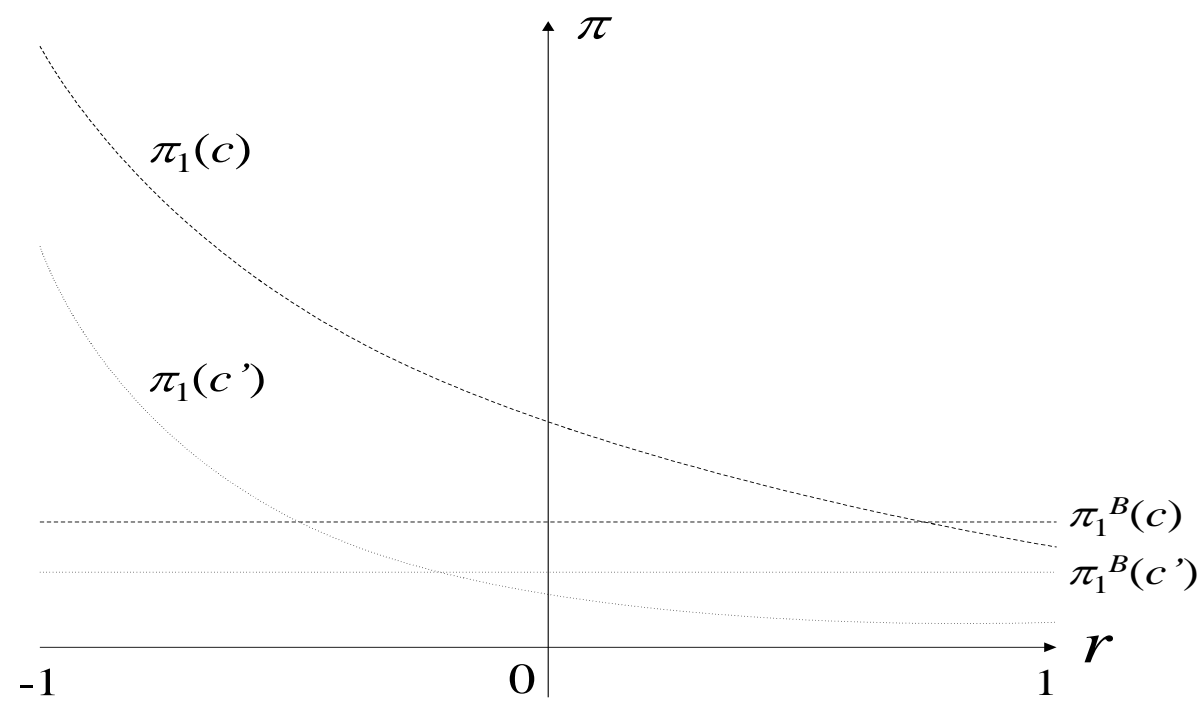

Figure 1: Bundling Incentive for a Follower of Enterprise 
The economic intuition is if a firm bundles two high complementary goods, then it will lose a monopoly profit. If a firm does not bundle two high complementary products, then the firm will obtain a monopoly profit. On the contrary, if a firm bundles two high substitution goods, then the firm obtains a high profit by selling two homogeneous goods at the same time. If a firm does not bundle two high substitution products, then the consumer only buys one of the two substitution goods. This induces the firm's profit to decrease.

Proposition 1: When two products have high complementary, it is good for a firm not to bundle. When two products have high substitution, it is good for a firm to bundle.

\section{Does a Stackelberg Follower Become a Stackelberg Leader?}

In the no bundling case, whether a Stackelberg follower can become a Stackelberg leader depends on the relationship for two goods. From Equation (6), $\pi_{1}-\pi_{2}>0$, if and only if $r<0.6$ for all $\beta$ and $c$. In other words, when two products have a low substitution relationship, the profit for a Stackelberg follower will be higher than the profit for a Stackelberg leader under the no bundling case.

In the bundling case and according to Equation (6'), it can be found that $\pi_{1}^{B}-\pi_{2}^{B}>0$, if and only if $r<$ 0.7324 for all $\beta$ and $c$. This implies that when two products have a low substitution relationship, the profit for a Stackelberg follower will be higher than the profit for a Stackelberg leader under the bundling case.

Comparing the results of the no bundling case and the bundling case, it can be found that when two products have low substitution, the profit for a Stackelberg follower is always higher than the profit for a Stackelberg leader no matter under the no bundling case or the bundling case. When two products have high substitution, the Stackelberg leader has a first mover advantage. On the contrary, if two products have low substitution, then although the Stackelberg leader has a first mover advantage, the Stackelberg follower also has an advantage in differential products. When two products have low substitution, or are independent or complementary, the advantage of differential products for a Stackelberg follower is that it will surpass the first mover advantage for the Stackelberg leader.

In practice, it is often seen that a firm bundles low substitution goods. For example, Microsoft bundles its Internet browser with its operating system (DeLong, 1998). Financial institutions bundle credit cards with airport services. Tourism bundles travel programs with plane tickets, insurance service, and hotel, etc. Moreover, French court judges that it is anti-law that computer maker Acer bundles its notebook computers with Microsoft's Windows XP (Internet News, 2007).

Proposition 2: Under the bundling case, only if two products has low substitution will a Stackelberg follower become a Stackelberg leader.

\section{Comparison of Social Welfare}

Equations (7) and (7') show that when $r \in(-1,1), S W^{B}<S W$. The geometric pictures for social welfare under the no bundling case and under the bundling case are shown in Figure 2. It shows that the social welfare under the no bundling case is better than the social welfare under the bundling case. In other words, the social welfare will decrease when the Stackelberg follower bundles goods. This result is very different from the result in the previous literature that tires not to decrease social welfare (Adams and Yellen, 1976; Schmalensee, 1984; Burstein, 1960).

The intuition is that because a follower has a disadvantage in the Stackelberg model, and the follower's disadvantage induces the quantities of $x$ and $y$ under the bundling case to be less than the quantities of $x$ and $y$ under the no bundling case, then social welfare under the bundling case is less than social welfare under the no bundling case. Although this result is the same as Martin (1999), this paper has extended a product's characteristic to substitution goods, independent goods, and complementary goods.

Proposition 3: Social welfare will decrease when a Stackelberg follower bundles goods. 


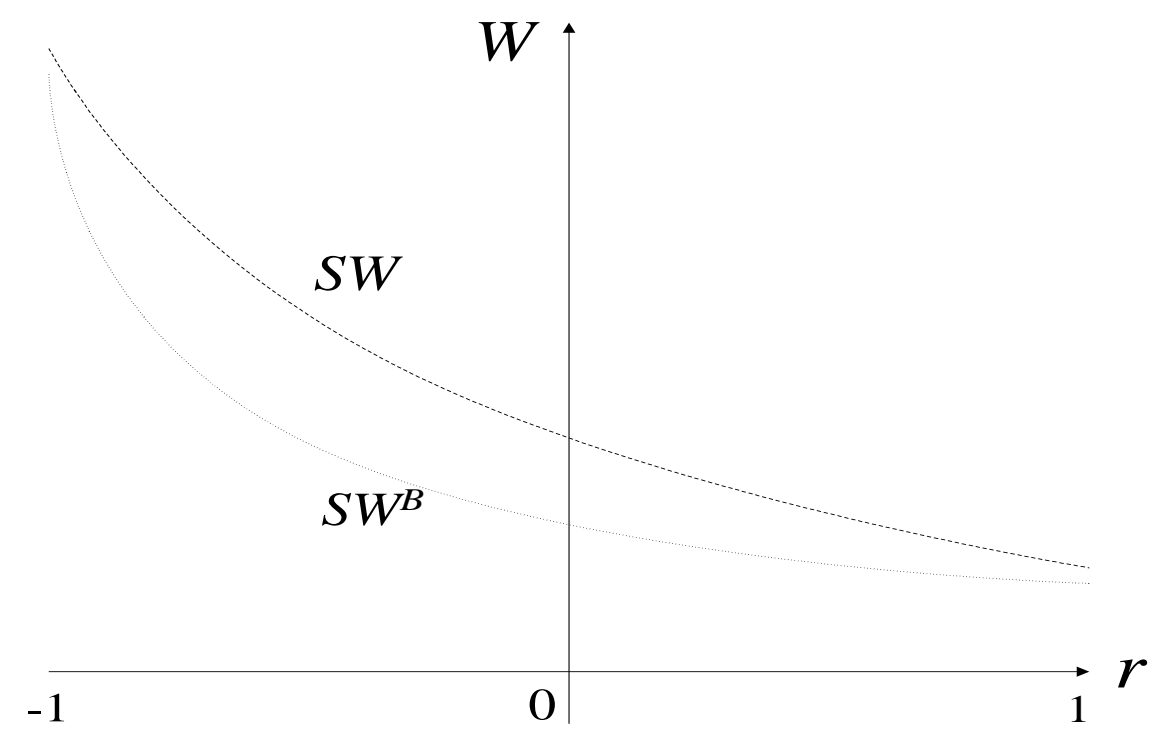

Figure 2: Comparison for Social Welfare

\section{CONCLUSION}

Bundling is a common commercial action for extracting profit from consumers and a rival. This paper extends the kinds of bundling products, including substitute goods, independent goods, and complementary goods. The market structure is a Stackelberg model. Based on the first mover advantage for a Stackelberg leader, the economic effect of bundling for a Stackelberg follower is discussed in this paper.

Some conclusions are found herein. If two products have high substitution, then the Stackelberg follower has an incentive to bundle and sell them for higher profit. On the contrary, if two products have low substitution, then it is good for the Stackelberg follower to sell them without bundling. When two products have low substitution, the profit for the Stackelberg follower will surpass the profit for the Stackelberg leader no matter if under the bundling case or under the no bundling case. Finally, social welfare will decrease when the Stackelberg follower bundles goods.

\section{REFERENCES}

1. Adams, W., and J. Yellen, (1976). "Commodity bundling and the burden of monopoly," Quarterly Journal of Economics, Vol. 90, pp.475-498.

2. Bakos, B. and E. Brynjofsson, (1999). "Bundling information goods: pricing, profit and efficiency," Management Science, Vol. 45, pp.1613-1630.

3. Burstein, M.L. (1960). "The economics of tie-in sales," Review of Economics and Statistics, Vol. 42, pp.68-73.

4. Chen, Y. (1997). "Equilibrium product bundling,” Journal of Business, Vol. 70, pp.85-103.

5. DeLong, J.V. (1998). "Don't repeat IBM debacle," Wall Street Journal Europe, Vol. 4, March, p.6.

6. Dixit, A. (1979). "A model of duopoly suggesting a theory of entry barriers," Bell Journal of Economics, Vol. 10, pp.20-32.

7. Internet News, (2007). <http://www.channelregister.co.uk/2007/09/26/acer laptop_microsoft_windows french ruling/>

8. MacAfee, R.P., J. MacMillan, and M. Whinston, (1989). "Multiproduct monopoly, commodity bundling and correlation of values," Quarterly Journal of Economics, Vol. 104, pp.371-383.

9. Martin, S. (1999). "Strategic and welfare implications of bundling," Economics Letters, Vol. 62, pp.371-376.

10. Salinger, M. (1995). “A graphical analysis of bundling,” Journal of Business, Vol. 68, pp.85-98. 
11. Schmalensee, R. (1982). "Commodity bundling by single products monopolies," Journal of Law and Economics, Vol. 25, pp.62-72.

12. Schmalensee, R. (1984). "Gaussian demand and commodity bundling," Journal of Law and Economics, Vol. 57, pp.211-230.

13. Spence, A.M. (1976). "Product differentiation and welfare," American Economic Review, Vol. 66, pp.407-414.

14. Vaubourg, A.G. (2006). "Differentiation and discrimination in a duopoly with two bundles," International Journal of Industrial Organization, Vol. 24, pp.753-762.

\section{$\underline{\text { NOTES }}$}

